\title{
THE ROLE OF INFORMATION ON CONSUMERS' PREFERENCES FOR LOCALLY PRODUCED APPLES IN TRADITIONAL RURAL AREAS
}

\section{$\underline{\text { Petjon Ballco }}^{a, b}$, Azucena Gracia ${ }^{a, b^{*}}$}

${ }^{a}$ Unidad de Economía Agroalimentaria y de los Recursos Naturales, Centro de Investigación y Tecnología Agroalimentaria de Aragón-CITA (Zaragoza,agracia@cita-aragon.es; pballco@cita-aragon.es).

${ }^{b}$ Instituto Agroalimentario de Aragón-IA2 (CITA-Universidad de Zaragoza).

\begin{abstract}
Fresh fruits cultivated in traditional areas are gaining consumers' interest due to environmental and social benefits, and most importantly, the sensory characteristics (taste, texture) they possess. This research focused on two apple varieties "Golden", and "Reineta" produced in the region of Aragón along the "Ebro River" and in a rural hilly area "Manubles", which has a long tradition on apple production. We measure consumers' valuation of apples produced in this rural area through a choice experiment with two treatments. In treatment $\mathrm{A}$, consumers chose based on the information provided (rural area and cultivation characteristics), and then inspected and tasted the apples (as in a real purchase). In treatment B, consumers first visually inspected and tasted the apples and then chose the most preferred alternative. Results showed that consumers were willing to pay higher prices for the "Golden" than the "Reineta" variety, especially when experiencing taste before choice (Treatment B). Conversely, higher premiums were paid when the apples were presented with the rural area (Manubles) and cultivation information first, and then were tasted (Treatment A). These results highlight the importance of using sensory analysis in choice experiments and reveal that product information might increase consumers' expectations, which may change after taste.
\end{abstract}

Keywords: Apples, Aragon, choice experiment, Golden, Manubles, Spain, willingness to pay.

\section{Introduction}

Apples are one of the most important fruits produced and consumed worldwide. In Europe, apples are the second most consumed fruit and in Spain, the consumption ranks behind that of oranges and bananas. The apple market is highly competitive driven by a high range of prices; however, the rest of the apple attributes (variety, sensory aspects, brand) are poorly differentiated, thus the product is mainly traded as a commodity. This is also reflected in the low presence of apple varieties, which among thousands available, the most important international standard varieties in Europe are the 'Golden Delicious' and 'Gala' (Jakobek et al., 2020). Two apple attributes experiencing rapid growth are the variety and local. For local apples, suggested reasons for consumers' interest include supporting the local economy, local farmers, and being fresh and tasty (Bernard and Liu, 2017). Along with these reasons, the sensory aspects (taste, color, texture) are important factors when choosing apples. Recent research that analyzed consumer preferences and the willingness to pay (WTP) for apple quality attributes (Hong et al., 2018), found that superior texture and flavor characteristics positively affects consumers' WTP. Therefore, following this stream of literature, we measure consumers' valuation for two apple varieties (mainstream 'Golden Delicious' and local 'Reineta') produced in two traditional production areas (the hilly rural area 'Manubles' and the valley area 'Ebro river'). A choice experiment examined consumer preferences between apple alternatives and a no-buy option. Sensory aspects were also considered and half of the consumers first inspected and tasted the apples before choosing their most preferred product, while the other half first evaluated the products based on the information as in a real situation and then tasted them.

\section{Materials and methods}

\subsection{Participants and implementation}

To measure consumers' valuation of apples, an experiment with two treatments ensured that the recruited participants were representative food buyers and had experience with the good (Harrison and List, 2004). The study was conducted in Aragon (Spain) in fall 2019 (the apple season). The participants lived in the capital city of Aragón. Only consumers of apples who were frequent food shoppers older than 18 years old participated in the experiment. The participants were recruited through consumers' associations, universities, technological centers, and town hall centers. The experiment was divided into 22 sessions with 10 participants per session, reaching 195 participants. Upon their arrival, the participants received information on the main purpose of the experiment and signed an informed consent form of participation. Next, they received information regarding the apple varieties and the place of production and then were randomly allocated in one of the two treatments. In treatment A, the participants first chose their most preferred apple from the choice tasks. Afterward, they inspected and tasted the product and were asked to indicate their global liking using a hedonic scale from 1 (not at all) to 9 (very). In treatment B, they first inspected and tasted the apples giving their hedonic ratings, and afterward, chose their most preferred 
alternative from the choice tasks. Finally, they reported apple purchase and consumption habits, sociodemographics, and personal characteristics.

\subsection{Choice experiment design}

The first step in designing the choice experiment was to select the product (apples) and the levels (price, apple variety, and place of production) (Table 1).

Table 1. Apple attributes and levels

\begin{tabular}{cc}
\hline Attribute & Level \\
\hline Price $(€ / \mathrm{kg})$ & $1 € / \mathrm{kg}-2 € / \mathrm{kg}-3 € / \mathrm{kg}-4 € / \mathrm{kg}$ \\
Apple variety & Golden \\
& Reineta \\
Place of production & Manubles \\
\hline
\end{tabular}

The price levels were set based on the market prices of the apple season of 2019. The choice tasks were generated following the Street and Burgess (2007) approach. The design to estimate the main effects with three attributes with 4, 2, and 2 levels generated eight choice tasks. Thus, each respondent had to choose eight times between two designed alternatives (A and B) and a no-buy option.

\subsection{Model specification and estimation}

The utility function is derived from the random utility theory and the theory of Lancaster (Lancaster, 1966), and is specified as follows:

$\mathrm{U}_{\mathrm{njt}}=\mathrm{ASC}+\beta_{1}$ PRICE $_{\mathrm{njt}}+\beta_{2} \mathrm{GOLDEN}_{\mathrm{njt}}+\beta_{3} M A N U B L E S+\varepsilon_{\mathrm{njt}}$

where $n$ is the number of respondents, $j$ represents the alternatives in the choice sets $(\mathrm{A}, \mathrm{B}$, and the no-buy option), and $t$ the number of sets. The $\beta$ are parameters to be estimated, and the ASC represents the specific alternative coded as a dummy variable with the value of 1 for alternatives $\mathrm{A}$ and $\mathrm{B}$ and 0 for the no-buy option. The price variable (PRICE) is defined according to the price levels in the design. The attributes of variety (GOLDEN) and place of production (MANUBLES) enter the model as dummy variables. Instead of assuming homogenous preferences, heterogeneity is allowed and an Error Component Random Parameters Logit model (EC-RPL) with correlated errors was estimated using the NLOGIT 5.0.

\section{Results and discussion}

From the total sample ( $\mathrm{n}=195)$, about $80 \%$ of the participants did the food shopping (Table 2).

Table 2. Sociodemographic and economic characteristics of the sample

\begin{tabular}{|c|c|c|c|c|}
\hline & Population & $\begin{array}{c}\text { Pool } \\
n=195\end{array}$ & $\begin{array}{c}\text { Treatment A } \\
n=96\end{array}$ & $\begin{array}{c}\text { Treatment B } \\
n=99\end{array}$ \\
\hline Female $(\%)[0.014(0.907)]^{\mathrm{a}}$ & $51.7^{1}$ & 60.0 & 60.42 & 59.6 \\
\hline Age (average) $[0.867(0.193)]^{b}$ & $48.3^{2}$ & 50.6 & 51.69 & 49.56 \\
\hline \multicolumn{5}{|l|}{$\operatorname{Age}(\%)[0.665(0.956)]^{\mathrm{a}}$} \\
\hline $18-34$ & $20.6^{1}$ & 21.03 & 19.79 & 22.22 \\
\hline $35-44$ & $18.4^{1}$ & 13.85 & 13.54 & 14.14 \\
\hline $45-54$ & $18.7^{1}$ & 23.08 & 25.00 & 21.21 \\
\hline $55-64$ & $17.2^{1}$ & 20.00 & 18.75 & 21.21 \\
\hline$\geq 65$ & $25.1^{1}$ & 22.05 & 22.92 & 21.21 \\
\hline \multicolumn{5}{|l|}{ Education level (\%) $[0.695(0.706)]^{\mathrm{a}}$} \\
\hline Primary & $34.3^{3}$ & 26.67 & 26.04 & 27.27 \\
\hline Secondary & $26.5^{3}$ & 26.15 & 23.96 & 28.28 \\
\hline Higher & $39.5^{3}$ & 47.18 & 50.00 & 44.44 \\
\hline \multicolumn{5}{|l|}{ Income level $(\%)^{\mathrm{e}}[8.192(0.146)]^{\mathrm{a}}$} \\
\hline$\leq 1500 € /$ month & N/A & 30.25 & 37.5 & 23.23 \\
\hline $1501-2500 € /$ month & N/A & 18.46 & 17.71 & 19.19 \\
\hline $2501-3500 € /$ month & N/A & 16.92 & 17.71 & 16.16 \\
\hline$>3500 € /$ month & & 8.72 & 9.38 & 8.08 \\
\hline
\end{tabular}


Do/not indicate

Household size $[-0.784(0.2169)]^{\mathrm{b}}$

Shopping the food $[0.552(0.907)]^{\mathrm{a}}$
25.64

N/A

N/A

N/A

46.15
2.77
17.71

2.71

32.29

47.92

44.44

Note: ${ }^{a} \chi 2$-square (p-value) test between treatments $(\chi 2 \mathrm{gl}=1 ; \alpha=0.05=3.84 ; \chi 2 \mathrm{gl}=2 ; \alpha=0.05=5.99 ; \chi 2 \mathrm{gl}=3 ; \alpha=$ $0.05=7.85 ; \chi 2 \mathrm{gl}=4 ; \alpha=0.05=9.49) .{ }^{\mathrm{b}}$ t-value of Student's test. ${ }^{1}$ INE (2019). ${ }^{2}$ IAEST (2020). ${ }^{3}$ EUROSTAT (2019). The participants were divided into the two treatments (treatment $A=96$ and treatment $B=99$ ). The whole sample is representative of the town population in terms of gender and age. The p-values of the chi-squared tests indicate that the null hypothesis of equality between treatments cannot be rejected for all the characteristics (gender, age, education level, income, and food shopping frequency), meaning that differences between treatments did not exist. Besides, the t-test proved that the null hypothesis of equality between treatments cannot be rejected for age and household size, indicating that differences between treatments did not exist. More females $(60 \%)$ than males participated in the study with an average age of 50 years old. Regarding the level of education, people with primary studies were under-represented, while higher educated people were over-represented.

The utility model (Eq.1) assumed price to be a fixed coefficient, while the rest of attributes-levels were random following a normal distribution. From these parameters, an EC-RPL model with correlated errors, and the consumers' WTPs were estimated (Table 3).

Table 3. Estimates for the EC-RPL with correlated errors model

\begin{tabular}{|c|c|c|c|c|c|c|}
\hline & \multicolumn{2}{|c|}{ Whole sample } & \multicolumn{2}{|c|}{ Treatment A } & \multicolumn{2}{|c|}{ Treatment B } \\
\hline Attributes & Coefficient & Z-ratio & Coefficient & Z-ratio & Coefficient & Z-ratio \\
\hline \multicolumn{7}{|c|}{ Mean estimation } \\
\hline ASC & $3.156 * * *$ & 11.90 & $3.361 * * *$ & 7.50 & $2.726 * * *$ & 8.83 \\
\hline PRICE & $-0.812 * * *$ & -22.11 & $-0.779 * * *$ & -15.04 & $-0.826 * * *$ & -15.5 \\
\hline GOLDEN & $1.157 * * *$ & 6.18 & $1.121 * * *$ & 4.13 & $1.288 * * *$ & 5.22 \\
\hline MANUBLES & $0.803 * * *$ & 6.62 & $0.830 * * *$ & 4.69 & $0.730 * * *$ & 4.69 \\
\hline \multicolumn{7}{|c|}{ Standard deviation of parameters } \\
\hline GOLDEN & $2.203 * * *$ & 12.81 & $2.199 * * *$ & 8.20 & $1.976 * * *$ & 9.06 \\
\hline MANUBLES & $1.017 * * *$ & 8.32 & $1.012 * * *$ & 5.96 & $0.795 * * *$ & 3.07 \\
\hline$\sigma$ & $2.002 * * *$ & 10.50 & $2.199 * * *$ & 6.98 & $2.039 * * *$ & 6.95 \\
\hline \multicolumn{7}{|c|}{ WTP (€/Package $)$} \\
\hline GOLDEN & $1.424 * * *$ & 5.92 & $1.438 * * *$ & 3.93 & $1.558 * * *$ & 5.07 \\
\hline MANUBLES & $0.988 * * *$ & 6.80 & $1.064 * * *$ & 4.64 & $0.884 * * *$ & 5.02 \\
\hline \multicolumn{2}{|c|}{ Number of observations } & 1536 & & 768 & & 768 \\
\hline \multicolumn{2}{|c|}{ McFadden Pseudo R-square } & 0.27 & & 0.28 & & 0.25 \\
\hline \multicolumn{2}{|l|}{ Log-likelihood } & -1228.7 & & -602.2 & & -629.76 \\
\hline
\end{tabular}

$\mathrm{WTP}=$ willingness to pay; $* * *=$ significance at $1 \%$

As expected, the PRICE coefficients were negative and statistically significant meaning that the utility of consumers decreases as price increases. In addition, the ASC is statistically positive indicating that the utility for consumers was higher when choosing any of the designed alternatives than the no-buy option. The positive and statistically significant values of the parameter estimate for GOLDEN and MANUBLES indicated that the utility for the 'Golden' variety and the apples produced in the rural area of 'Manubles' were higher than the utility for the 'Reineta' variety, and apples produced along the Ebro river. Finally, the hypothesis of correlation across utility is corroborated, since the error component for the alternative specific constant $(\sigma)$ is statistically significant.

Regarding the WTP estimates, in treatment A, the participants were willing to pay less for the 'Golden' variety apple than in treatment B, indicating that after inspecting and tasting the same variety (Golden) the premium price increased. Conversely, the WTP in treatment A for the apples from the rural area 'Manubles' was higher than in treatment $\mathrm{B}$, indicating that information on the taste and appearance diminished the premium price paid. Further analysis is required to profile this segment of consumers using the hedonic liking scales and the socio-demographic characteristics. These results demonstrate that information on the sensory characteristics might increase expectations, which may change preferences after taste. Therefore, to value product attributes for fresh produce, it is important the use sensory analysis in choice experiments. 
These results have some important implication for producers and retailers. Producers should clearly provide important information to retailers emphasizing the apple variety and the most appropriate way of consumption (e.g., fresh and/or cooked). Providing some sensory information (e.g., Mealy in the case of the Reineta variety) would also be helpful. Besides delivering the above information to consumers, retailers should provide free sample of apples so consumers who are not familiar with the real taste of the apple variety (e.g., Reineta in our case) experience the sensory attributes before deciding to purchase it. This strategy will create a balance between the high expectations created before purchase and the negative taste experience, it will reduce the negative word-of-mouth communication regarding the taste of the product to friends and relatives, and will ensure the continuous repurchase of the product in case of positive evaluations.

\section{References}

Bernard, J. C., and Liu, Y. (2017). "Are beliefs stronger than taste? A field experiment on organic and local apples". Food Quality and Preference, 61:55-62.

EUROSTAT Population aged 25-64 by educational attainment level, sex and NUTS 2 regions (\%). 2021.

Harrison, G.W. and List, J.A. (2004). "Field experiments", Journal of Econ. Lit., 42(4):1009-1055.

Hong, Y. A., Gallardo, R. K., Silva, M., and Orozco, J. F. (2018). "College Students' Preferences and Willingness to Pay for Fresh Apple Varieties in Peru". J. of Food Distr. Research, 49:38-56.

IAEST Fichas territoriales. Zaragoza. Estadística Local.

INE. (2019). INEbase / Demografía y población /Cifras de población y Censos demográficos.

Jakobek, L., Ištuk, J., Buljeta, I., Voća, S., Žlabur, J. Š., \& Babojelić, M. S. (2020). Traditional, indigenous apple varieties, a fruit with potential for beneficial effects: their quality traits and bioactive polyphenol contents. Foods, 9(1), 52.

Lancaster, K. (1966). “A new approach to consumer theory”. Journal of Political Economy, 74(2):132-157.

Street, D. and Burgess, L. (2007). The construction of optimal stated choice experiments. John Wiley \& Sons Inc., New Jersey. 